\title{
IAM helpful or not?
}

\section{The inner workings of Integrated Assessment Models need to be made more transparent.}

Integrated Assessment Models (IAMs) are increasingly being used to inform policymakers about the likely societal and economic consequences of climate change. An example of such a study is the Letter in this issue by Frances Moore and Delavane Diaz (page 127), which uses a widely applied IAM called DICE to show how the effects of climate change on economic growth affect estimates of the social cost of carbon; see also the accompanying News \& Views article by Andries Hof (page 99).

IAMs are potentially powerful tools, and results from them have already been incorporated into IPCC Assessment Reports. But just how generally reliable and informative are the projections emanating from the present generation of models?

A typical IAM combines a simple model of the Earth's climate system with a social science or economic model. IAMs necessarily include assumptions - and simplifications - about how the physical climate system works as well as the interaction of demographic, political and economic variables. It is essential, if IAMs are to effectively help shape climate change policy, that these underlying assumptions as well as model inputs are made explicit. Only then can experts probe the robustness and meaningfulness of their outputs. Just as importantly, the equations driving IAMs need to be specified so as to allow users to understand the mechanisms responsible for the model projections and predictions. Such transparency should help avoid the impression that IAMs are 'black boxes', the inner workings of which are inscrutable and impossible even for experts to assess whether model projections are realistic.

The issues of model robustness and consistency between models have occupied the minds of climate researchers for years. A major aim of the Coupled Model Intercomparison Project is, for example, to assess and improve the performance and reliability of global coupled ocean-atmosphere general circulation models used to predict future climate under a variety of emissions scenarios. The design and organization of the latest phase of the project - CMIP6 - was finalized at a meeting in October 2014 in Germany; full details should be available in April this year (http://www.wcrp-climate.org/ wgcm-cmip/wgcm-cmip6).

IAM researchers are now emulating the efforts of climate researchers by instigating their own model inter-comparison projects (MIPs). This is likely to be a fruitful enterprise. To illustrate the point, in a Review on page 119 of this issue, Massimo Tavoni and colleagues discuss what can be learned from a recent MIP in the context of post-2020 climate negotiations, and actions needed at a regional level to help meet the widely discussed $2{ }^{\circ} \mathrm{C}$ target.

We can expect many similar studies to appear over the coming months and years. It will be interesting to see how they fare.

\section{Coastal conundrums}

\section{Choosing and implementing adaptation measures to protect coastal populations and infrastructure from sea-level rise and storm surges is no easy matter.}

Climate change adaptation involves many factors, including the likely social and economic impacts of adaptation measures themselves, and the political niceties of adaptation planning. This month, three research papers illustrate these issues nicely.

The millions of people that live and work along Vietnam's vast Mekong Delta are vulnerable to the impacts of sea-level rise, and the effects of upstream development. On page 167, Alex Smajgl and colleagues describe some of the difficult choices faced by the Vietnamese government in tackling these interrelated challenges, and some of the tensions and divisions that have emerged within the policy arena.

It seems that some Vietnamese policymakers favour investment in such things as the building of large-scale coastal defences - the so called 'hard' adaptation options. Others instead advocate 'softer' measures such as land use-related adaption options. Smajgl et al. argue that this disagreement between these two factions has resulted in 'political adaptation paralysis'. Based on their analysis, the researchers believe that a balance between hard and soft options is the way to go. The implications of their finding, its relevance to other parts of the world where coastal floodplains face similar problems, and the importance of recognizing political processes in climate adaptation are further discussed by Declan Conway on page 105. As he notes, in the case of the Mekong Delta, the political dimension also involves countries involved in development and water management upstream of the delta itself.

In a separate paper (page 153), Leslie Auerbach and colleagues consider the case of the Ganges-Brahmaputra tidal delta plain of southwest Bangladesh. Specifically, they show that, through reduced sedimentation, the landscape of a low-lying island in the delta experienced a net elevation loss in the years after embankments were constructed in the 1960s. When cyclone Aila breached the island's protective embankments in 2009, this loss of elevation caused major flooding and inundation. Based on their research, Auerbach and colleagues argue that human manipulation of the environment can itself amplify the threat posed by climate change to the region.

Orencia Duràn Vinent and Laura Moore (page 158) also consider the landscape response to climate change, in this case in relation to barrier islands protecting mainland shores. They demonstrate that the actual morphology of such islands can be bistable due to dynamical changes in the balance of competing effects of storm erosion, sea-level rise, and the aeolian and biological processes. This means that even seemingly mild storm conditions, for example, can cause rapid and catastrophic state transitions, making the impacts of sea-level rise much worse.

Between them, these studies should open eyes to some of the complexities of climate adaption planning for coastal regions. 